\title{
Interleukin 10 gene rs1800896 polymorphism is associated with the risk of prostate cancer
}

\author{
Hao Chen ${ }^{1}$, Jilei Tang ${ }^{2}$, Nan Shen $^{3}$ and Kewei Ren ${ }^{4}$ \\ ${ }^{1}$ Department of Urology, The First Hospital of Jiaxing, Jiaxing 314001, China \\ ${ }^{2}$ Department of Orthopedics, Qidong People's Hospital, Nantong 226200, China \\ ${ }^{3}$ Department of Clinical Pharmacy, The Affiliated Jiangyin Hospital of Southeast University Medical School, Jiangyin 214400, \\ China \\ ${ }^{4}$ Department of Orthopedics, The Affiliated Jiangyin Hospital of Southeast University Medical School, Jiangyin 214400, China \\ Correspondence to: Kewei Ren, email: rkwmedicine@tom.com \\ Keywords: interleukin-10, polymorphism, prostate cancer, meta-analysis \\ Received: May 10, $2017 \quad$ Accepted: June 30, $2017 \quad$ Published: August 03, 2017 \\ Copyright: Chen et al. This is an open-access article distributed under the terms of the Creative Commons Attribution License 3.0 \\ (CC BY 3.0), which permits unrestricted use, distribution, and reproduction in any medium, provided the original author and source \\ are credited.
}

\section{ABSTRACT}

\begin{abstract}
Numerous studies have uncovered the association of Interleukin-10 (IL-10) gene rs1800896 polymorphism with the risk of prostate cancer (PCa); however, their conclusions were inconsistent. Therefore, we conducted this meta-analysis to evaluate the role of $I L-10$ rs1800896 polymorphism in the risk of PCa. 16 eligible studies in 15 articles involving 6,301 cases and 6,510 controls were identified by researching PubMed, Google, CNKI, and EMBASE up to April 1, 2017. Our results revealed that IL-10 rs1800896 polymorphism was associated with the decreased risk of PCa under the homozygous model. Subgroup analysis by ethnicity revealed that rs1800896 polymorphism decreased the risk of PCa among Caucasians. In conclusion, IL-10 gene rs1800896 polymorphism is associated with the decreased risk of PCa. Larger studies with more diverse ethnic populations are needed to confirm these results.
\end{abstract}

\section{INTRODUCTION}

Prostate cancer (PCa) is the most common malignancy diagnosed in men and the second leading cause of cancer-related death for men in the United States [1]. The American Cancer Society estimates that 161,360 new PCa cases and 26,730 PCa deaths will occur in 2017 [2]. Widespread use of prostate-specific antigen (PSA) screening could reduce mortality of PCa. However, PSA screening may contribute to overdiagnosis and overtreatment [3]. New predictive biomarkers are becoming an urgent need, such as single nucleotide polymorphism (SNP) [4]. Remarkably, Xu et al. found that SNPs of four genes in the inflammation pathway, including interleukin-10 (IL-10) could significantly predict the risk of $\mathrm{PCa}$ [5].

$I L-10$ is a pleiotropic cytokine that modulates the function of several adaptive immunity-related cells [6]. $I L-10$ is known to suppress the functions of both $\mathrm{T}$ lymphocytes and macrophages, working as a general dampener of the immune and inflammatory responses [7]. Huang et al. found that $I L-10$ could suppress metastasis and growth of the tumor by inhibiting macrophage-derived angiogenic factors in vivo [8]. Richter et al. also found that $I L-10$ transfected into Chinese hamster ovary cells prevents tumor growth and macrophage infiltration [9]. In addition, overexpression of $I L-10$ was observed in PCa tissue by the analysis of type T1 and T2 cytokines in patients with $\mathrm{PCa}[10]$. Yu et al. also found $I L-10$ decreased stemness of human prostate cancer cells in vitro [11]. Based on these observations, $I L-10$ may provide insights about screening and therapeutic intervention on neoplastic patients.

Kingo et al. identified that $I L-10$ rs1800896 polymorphism may have an influence on $I L-10$ mRNA expression and the expression of $I L-10$ in vitro [12]. Recently, a host of studies [5, 13-26] attached importance to evaluating whether $I L-10$ rs 1800896 polymorphism had effects on the risk of PCa. Some studies yielded relations 
between $I L-10$ rs1800896 polymorphism and PCa risk $[16,19,22]$, but other studies could not $[5,13-15,17$, 18, 20, 21, 23-26]. Small sample sizes, low statistical power, and clinical heterogeneity may contribute to these conflicting results. Therefore, we conducted this metaanalysis to review available evidence and evaluate the effects of rs 1800896 polymorphism in $I L-10$ gene on PCa susceptibility in the overall population.

\section{RESULTS}

\section{Characteristics of the included studies}

We used the following searched terms like prostate cancer, prostatic neoplasm, prostate carcinoma, prostate neoplasms, polymorphism, polymorphisms, SNP, SNPs, rs1800896, Interleukin 10, IL-10 and IL10 to identify relevant articles. Totally 195 articles were identified after an electronic and manual search (PubMed, 74 articles; EMBASE, 65 articles; CNKI, 5 articles; Google, 51 articles). Then 67 duplicates and 96 articles unrelated to this topic were removed. 32 articles remained for further full-text review. 17 articles were excluded due to the following reasons: eight articles investigated other diseases rather than $\mathrm{PCa}$; three articles investigated other polymorphisms of $I L-10$ gene; one article did not provide detailed genotyping data; three articles were reviews or meta-analyses; one article was excluded due to overlapping information with another study. One article was divided into two studies because it contains two different racial groups. Finally, 16 eligible studies in 15 articles with 6,301 patients and 6,510 controls were included in this meta-analysis. The selection for eligible studies was presented in Figure 1. Most of the included studies [5, 15, 16, 18-22, 24, 25] were population-based studies, focusing on Caucasians. In addition, we found that five studies $[13-15,21,27]$ did not conform to Hardly-Weinberg equilibrium (HWE). The phenomenon may be partly attributed to genotyping error, population stratification and selection bias in the recruitment of controls. Moreover, the Newcastle-Ottawa Scale (NOS) scores of all included studies ranged from 5 to 7 stars, suggesting that these studies were of high methodological quality. The detailed characteristics of included studies are listed in Table 1.

\section{Quantitative analysis}

The findings of our meta-analysis uncovering the association between $I L-10$ rs 1800896 polymorphism and PCa was summarized in Tables 2 and 3. The meta-analysis revealed that individuals carrying GG genotypes had a 19\% lower risk of developing PCa compared to those who carried AA genotypes in the overall population (GG vs. AA: OR, 0.81; 95\% CI, 0.66-0.99, $P=0.044$, Figure $2)$. Stratification analyses were conducted according to ethnicity, HWE, SOC and genotyping method. Ethnicity subgroup analysis indicated that the risk allele of rs1800896 in the $I L-10$ gene was associated with the decreased risk of PCa among Caucasians in most of the comparisons (G vs. A: OR, 0.85; 95\% CI, 0.76-0.96, $P$ $=0.007$, Figure 3), while the opposite result was found among Asians in the allele model (G vs. A: OR, 1.44; 95\% CI, 1.06-1.97, $P=0.020$, Figure 3 ) and dominant model. In addition, we failed to find this significant association among Africans under five models (Table 3). Stratification analyses by SOC and genotyping method suggested that population-based studies or studies using MassARRAY method were easy to find the associations between $I L$ 10 rs1800896 polymorphism and risk of PCa. However, when stratified by HWE, there is no significant association in the HWE-positive groups or HWE-negative groups. Obviously, these studies deviating from HWE have effects on the overall results.

\section{Heterogeneity and publication bias}

High between-study heterogeneity was observed under five models. Meta-regression suggested that ethnicity $(P=0.163)$, HWE $(P=0.621)$ and genotyping method $(P=0.514)$ had no significant impact on the heterogeneity in ORs with $I L-10$ rs 180086 polymorphism except for SOC $(P=0.043)$. Consequently, SOC may be the main source of high heterogeneity. We assessed the sensitivity by omitting each study in turn to assess the effect of individual study on the overall estimated risk. The pooled ORs did not show a significant difference by removing any individual study, supporting that this metaanalysis was stable and trustworthy (GA vs. AA, Figure 4). Both Egger's and Begg's tests (GG vs. GA+AA, Figure 5) were used to evaluate the publication bias of this metaanalysis. No evidence of publication bias was found in this meta-analysis (Table 2).

\section{DISCUSSION}

The role of $I L-10$ in tumor pathogenesis and development is a double-edged sword. Many studies have revealed the significant association between $I L-10$ levels and poor prognosis. Moreover, $I L-10$ is also thought to promote tumor immune escape by diminishing anti-tumor immune response in the tumor microenvironment [28]. Richter et al. found $I L-10$ showed the anti-tumor effect on the suppression of angiogenesis and metastasis [9]. Notably, rs1800896 polymorphism in the $I L-10$ gene promoter could affect $I L-10$ production [29]. Recently, the association between the $I L-10$ rs180086 polymorphism and various cancers has been reported widely, including esophageal cancer [30], oral cancer [31], gastric cancer [32] and colorectal cancer [33]. Of course, $\mathrm{PCa}$ is also among these cancers that could not be ignored. In 2002, McCarron et al. found that $I L-10$ rs 1800896 polymorphism 
could decrease the risk of PCa in the United Kingdom [19]. The significant association was confirmed in the subsequent studies among Caucasians $[16,22]$. However, the remaining studies failed to uncover the association between the $I L-10$ rs 1800896 polymorphism and PCa risk in different races [5, 13-15, 17, 18, 20, 21, 23-25, 27].

To address this controversy, Shao et al. reviewed 10 studies involving 3,451 cases and 4,440 controls and performed a comprehensive meta-analysis in 2011 [34]. They found that there was no significant association between the $I L-10$ rs 1800896 polymorphism and the risk of PCa in the overall population [34]. In the subgroup analysis, negative results were also found among Caucasians and Asians [34]. In another meta-analysis involving 4846 cases and 5244 controls from 12 studies, Zou et al. [35] got the same findings as the meta-analysis conducted by Shao et al. [34]. In 2017, Ruan et al. [36] found that $I L-10$ rs1800896 polymorphism was not associated with the risk of $\mathrm{PCa}$ in overall populations. However, they found rs1800896 polymorphism might increase the risk of $\mathrm{PCa}$ among Asians in the stratification analysis of ethnicity [36]. In this study, we re-evaluated the role of $I L-10$ rs 1800896 polymorphism in the risk of PCa by meta-analysis involving 12,811 subjects. Our data found that $I L-10$ rs1800896 polymorphism was associated with the decreased risk of PCa. In addition, we think previous meta-analyses [34-36] had several limitations. First, Shao et al. [34] did not conduct a comprehensive research and omitted an article [5]. Second, Zou et al. [35] did not analyze the source of heterogeneity and conduct sensitive analysis to evaluate whether individual study could influence the overall result qualitatively. Third,

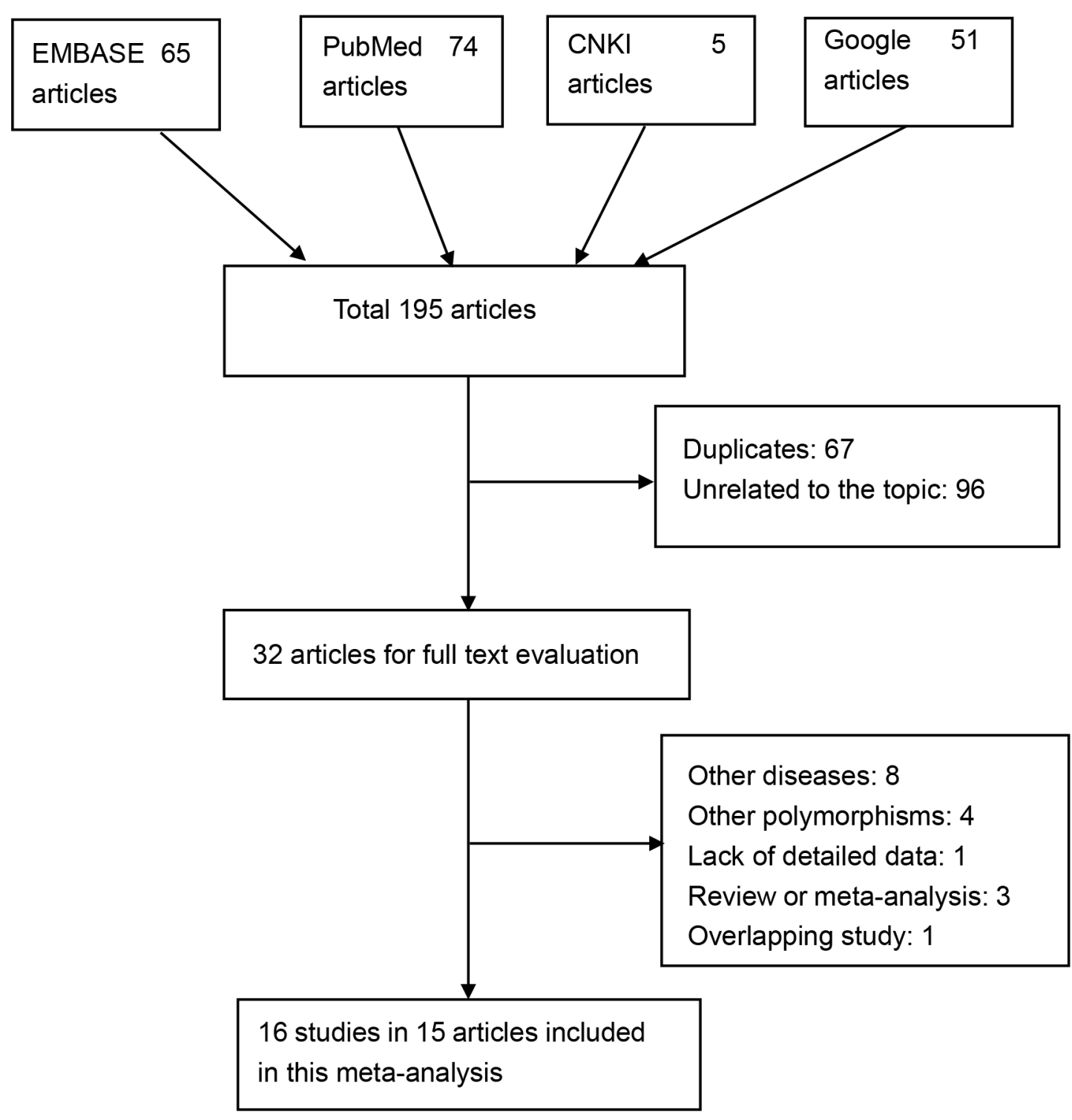

Figure 1: Selection of eligible publications included in this meta-analysis. 
Table 1: Characteristics of included studies for the association between $I L-10$ rs1800896 polymorphism and prostate cancer

\begin{tabular}{|c|c|c|c|c|c|c|c|c|c|c|c|c|}
\hline \multirow[t]{2}{*}{ Author+year } & \multirow[t]{2}{*}{ Country } & \multirow[t]{2}{*}{ Ethnicity } & \multirow[t]{2}{*}{ SOC } & \multirow{2}{*}{$\begin{array}{l}\text { Genotyping } \\
\text { method }\end{array}$} & \multicolumn{3}{|c|}{ Case } & \multicolumn{3}{|c|}{ Control } & \multirow[t]{2}{*}{ HWE } & \multirow[t]{2}{*}{ NOS } \\
\hline & & & & & GG & GA & $\mathbf{A A}$ & GG & GA & $\mathbf{A A}$ & & \\
\hline McCarron2002 & UK & Caucasian & $\mathrm{PB}$ & PCR & 56 & 113 & 78 & 57 & 120 & 46 & Yes & 7 \\
\hline Xu2005 & Sweden & Caucasian & PB & MassARRAY & 306 & 689 & 388 & 187 & 390 & 203 & Yes & 6 \\
\hline Michaud2006 & US & Mixed & PB & Taqman & 290 & 599 & 356 & 383 & 857 & 523 & Yes & 7 \\
\hline $\begin{array}{l}\text { Faupel- } \\
\text { Badger2008 }\end{array}$ & US & Caucasian & PB & Taqman & 85 & 251 & 173 & 73 & 194 & 115 & Yes & 6 \\
\hline Omrani2008 & Iran & Caucasian & $\mathrm{HB}$ & PCR & 5 & 31 & 5 & 2 & 98 & 3 & No & 5 \\
\hline Zabaleta2008 & US & Caucasian & $\mathrm{HB}$ & Taqman & 126 & 239 & 110 & 86 & 206 & 102 & Yes & 6 \\
\hline Zabaleta2008 & US & African & HB & Taqman & 7 & 38 & 21 & 13 & 74 & 42 & No & 6 \\
\hline Kesarwani2009 & India & Caucasian & PB & PCR & 12 & 78 & 69 & 45 & 103 & 111 & No & 6 \\
\hline Wang2009 & US & Caucasian & PB & Taqman & 56 & 130 & 69 & 83 & 117 & 57 & Yes & 6 \\
\hline Liu2010 & China & Asian & PB & PCR & 4 & 36 & 222 & 3 & 27 & 240 & Yes & 7 \\
\hline VanCleave2010 & US & African & $\mathrm{HB}$ & Taqman & 75 & 95 & 22 & 288 & 280 & 92 & Yes & 7 \\
\hline Niu2011 & China & Asian & $\mathrm{HB}$ & N/A & 18 & 56 & 24 & 20 & 26 & 42 & No & 6 \\
\hline Dluzniewski2012 & US & Caucasian & PB & MassARRAY & 100 & 212 & 146 & 104 & 242 & 112 & Yes & 7 \\
\hline Lanni2013 & Italy & Caucasian & PB & Taqman & 18 & 74 & 79 & 28 & 43 & 25 & Yes & 6 \\
\hline Horvat2015 & Croatia & Caucasian & $\mathrm{HB}$ & Taqman & 24 & 59 & 37 & 24 & 54 & 42 & Yes & 6 \\
\hline Winchester 2017 & US & Caucasian & PB & MassARRAY & 136 & 305 & 179 & 140 & 254 & 134 & No & 7 \\
\hline
\end{tabular}

SOC, source of controls; PB, population-based controls; HB, hospital-based controls; HWE, hardy-weinberg equilibrium; NOS, newcastle-ottawa scale.

Ruan et al. [36] did not include three studies [22, 25, 37] which actually conformed to the inclusion criteria. In addition, Ruan et al. extracted wrong genotype number of rs1800896 polymorphism from the study conducted by Wang et al. [16]. Consequently, the reliability of their results [34-36] should be interpreted with caution. We believe our meta-analysis has some strength over previous meta-analyses for the following reasons. One, we identified 16 studies including 6,301 cases and 6,510 controls with regard to rs1800896 polymorphism and the sample size of this meta-analysis was large enough. Two, sensitivity analysis indicated that our data about rs1800896 polymorphism were trustworthy and robust.

Recently, a study found $I L-10$ can completely prevent antigen-specific $\mathrm{T}$ cell proliferation by inhibition of the antigen-presenting capacity of monocytes through downregulation of class II major histocompatibility complex (MHC) antigens on monocytes [38]. The finding suggested a mechanism for tumor cells escaping from immune surveillance. In addition, AA homozygotes of rs1800896 polymorphism in the $I L-10$ gene could reduce the production of $I L-10$ [39]. Based on these observations, we guessed that less $I L-10$ was beneficial for immunological monitoring, reducing the possibility of tumor cell survival. It may partly explain the reason why $I L-10$ gene rs 1800896 polymorphism was associated with the decreased risk of PCa.

The stratified analyses further confirmed this significant association in population-based studies and studies using the genotyping method of MassARRAY. In addition, stratification analysis by ethnicity indicated that the $\mathrm{G}$ allele of rs 1800896 could decrease the risk of PCa among Caucasians (11 studies involving 4,438 cases and 3,600 controls) and increase the risk of PCa among Asians ( 2 studies containing 360 cases and 358 controls), indicating different racial inheritance of Caucasians and Asians. This discrepancy may partly attribute to ethnicityspecific effect and sample sizes. For Caucasians, the minor allele $\mathrm{G}$ frequency was 0.467 in this meta-analysis, which was much higher than that of Asians (0.164). We hypothesized that genetic heterogeneity, clinical heterogeneity, different genotyping methods and random errors may also be the potential reasons for different findings between Asians and Caucasians. In addition, sample sizes in the subgroup of Asians were relatively small, thus the findings of Asians may be underpowered. 


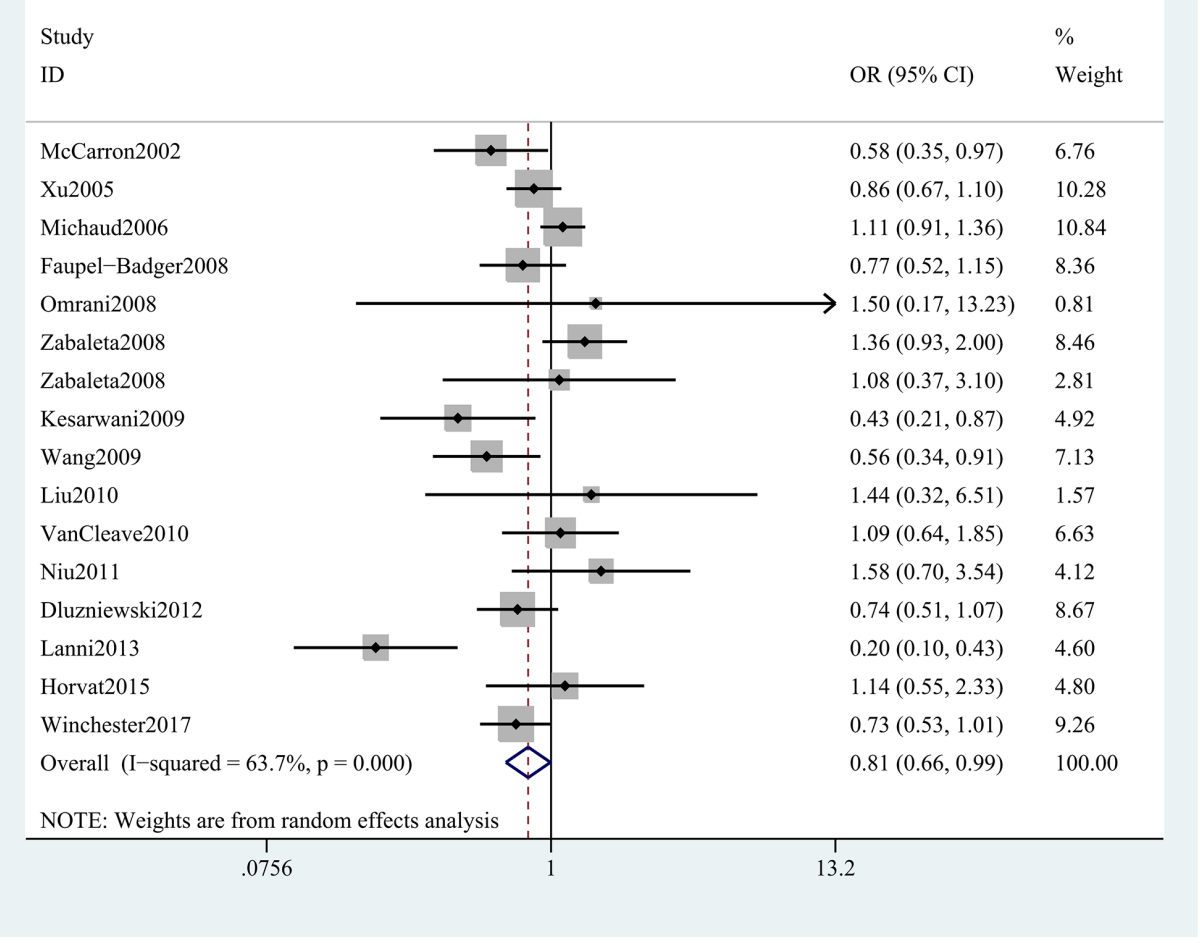

Figure 2: Forest plot shows odds ratio for the associations between $I L-10$ rs1800896 polymorphism and PCa risk (GG vs. AA).

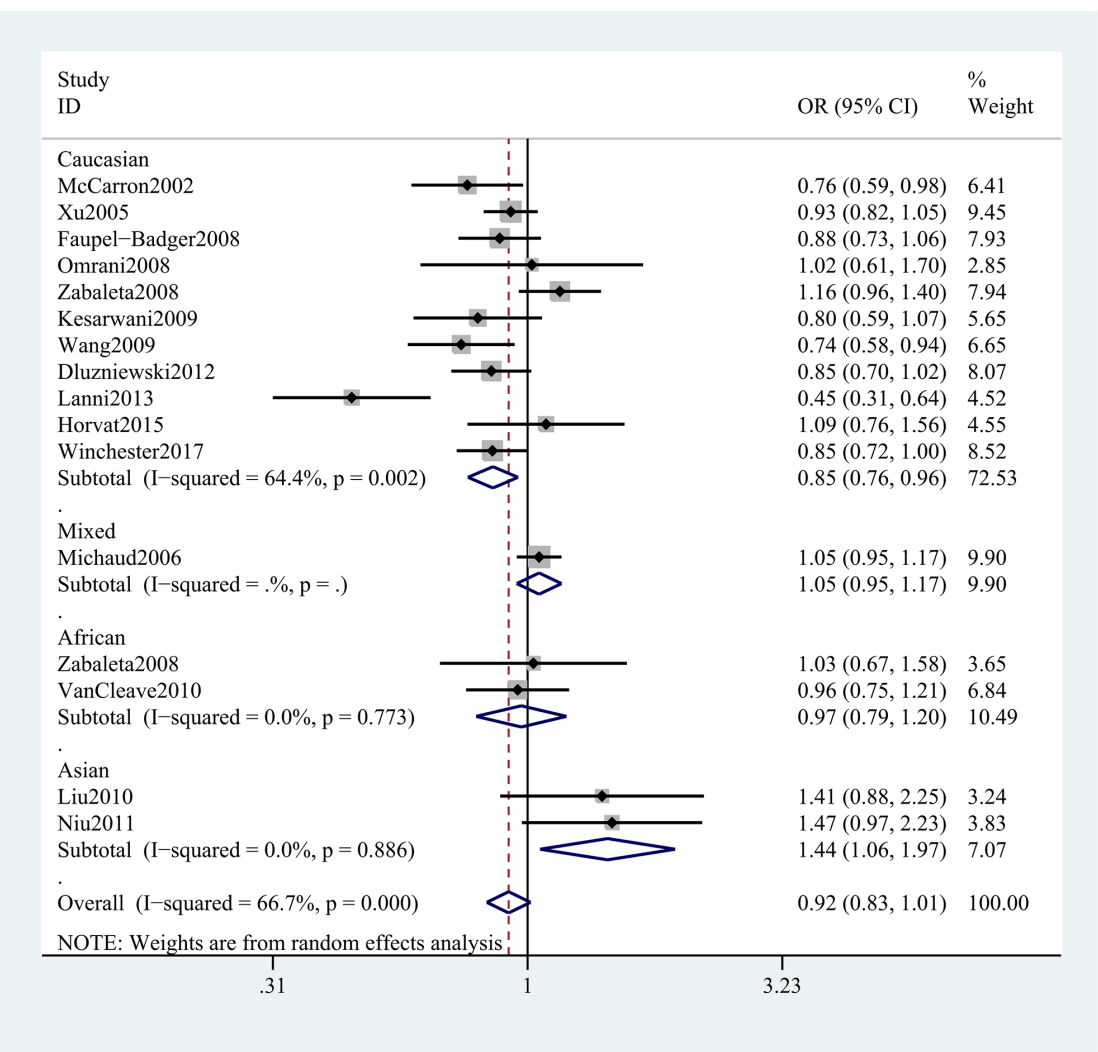

Figure 3: Stratification analyses of ethnicity between $I L-10$ rs1800896 polymorphism and PCa risk (G vs. A). 
Table 2: Meta-analysis for the effect of rs1800896 on the risk of prostate cancer

\begin{tabular}{|c|c|c|c|c|c|c|}
\hline \multirow[t]{2}{*}{ Genetic model } & \multicolumn{2}{|c|}{ Statistics } & \multicolumn{2}{|c|}{ Heterogeneity } & \multicolumn{2}{|c|}{ Publication bias } \\
\hline & OR(95\%CI) & $P$ & $\boldsymbol{P}_{\text {heterogeneity }}$ & $I^{2}(\%)$ & $\boldsymbol{P}_{\text {begg }}$ & $\boldsymbol{P}_{\text {Egger }}$ \\
\hline Allele (G vs. A) & $0.92(0.83,1.01)$ & 0.089 & $<0.001$ & 66.7 & 0.857 & 0.590 \\
\hline $\begin{array}{l}\text { Dominant } \\
\text { (GG+GA vs. AA) }\end{array}$ & $0.92(0.79,1.08)$ & 0.319 & $<0.001$ & 67.2 & 0.787 & 0.742 \\
\hline $\begin{array}{l}\text { Recessive (GG } \\
\text { vs. GA+AA) }\end{array}$ & $0.85(0.72,1.00)$ & 0.052 & $<0.001$ & 62.6 & 0.928 & 0.418 \\
\hline $\begin{array}{l}\text { Homozygous } \\
\text { (GG vs. AA) }\end{array}$ & $0.81(0.66,0.99)$ & 0.044 & $<0.001$ & 63.7 & 0.719 & 0.399 \\
\hline $\begin{array}{l}\text { Heterozygous } \\
\text { (GA vs. AA) }\end{array}$ & $1.02(0.85,1.23)$ & 0.814 & $<0.001$ & 72.0 & 0.787 & 0.938 \\
\hline
\end{tabular}

*Bold values are statistically significant $(P<0.05)$.

Table 3: Summary of the subgroup analyses in this meta-analysis

\begin{tabular}{|c|c|c|c|c|c|c|}
\hline Comparison & Category & Category & Studies & OR $(95 \%$ CI $)$ & $P$-value & $P$ for heterogeneity \\
\hline \multirow[t]{12}{*}{ G vs. A } & Ethnicity & Caucasian & 11 & $0.85(0.76,0.96)$ & 0.007 & 0.002 \\
\hline & & Mixed & 1 & $1.05(0.95,1.17)$ & 0.312 & N/A \\
\hline & & African & 2 & $0.97(0.79,1.20)$ & 0.786 & 0.773 \\
\hline & & Asian & 2 & $1.44(1.06,1.97)$ & 0.020 & 0.886 \\
\hline & SOC & PB & 10 & $0.85(0.75,0.96)$ & 0.008 & $<0.001$ \\
\hline & & HB & 6 & $1.10(0.97,1.24)$ & 0.125 & $<0.001$ \\
\hline & HWE & Positive & 11 & $0.90(0.80,1.02)$ & 0.097 & $<0.001$ \\
\hline & & Negative & 5 & $0.96(0.79,1.16)$ & 0.654 & 0.128 \\
\hline & Method & PCR & 4 & $0.91(0.70,1.17)$ & 0.452 & 0.117 \\
\hline & & MassARRAY & 3 & $0.89(0.81,0.97)$ & 0.006 & 0.625 \\
\hline & & Taqman & 8 & $0.90(0.77,1.07)$ & 0.230 & $<0.001$ \\
\hline & & N/A & 1 & $1.47(0.97,2.23)$ & 0.066 & N/A \\
\hline \multirow[t]{12}{*}{ GG+GA vs. AA } & Ethnicity & Caucasian & 11 & $0.81(0.69,0.95)$ & 0.009 & 0.014 \\
\hline & & Mixed & 1 & $1.05(0.90,1.24)$ & 0.525 & N/A \\
\hline & & African & 2 & $1.16(0.79,1.72)$ & 0.445 & 0.643 \\
\hline & & Asian & 2 & $1.96(1.02,3.78)$ & 0.043 & 0.102 \\
\hline & SOC & PB & 10 & $0.83(0.71,0.97)$ & 0.021 & 0.004 \\
\hline & & HB & 6 & $1.23(0.86,1.78)$ & 0.261 & 0.028 \\
\hline & HWE & Positive & 11 & $0.89(0.75,1.05)$ & 0.163 & 0.001 \\
\hline & & Negative & 5 & $1.04(0.64,1.68)$ & 0.870 & 0.002 \\
\hline & Method & PCR & 4 & $0.79(0.46,1.37)$ & 0.404 & 0.009 \\
\hline & & MassARRAY & 3 & $0.83(0.72,0.96)$ & 0.012 & 0.333 \\
\hline & & Taqman & 8 & $0.94(0.77,1.14)$ & 0.527 & 0.027 \\
\hline & & N/A & 1 & $2.82(1.51,5.24)$ & 0.001 & N/A \\
\hline
\end{tabular}

(Continued) 


\begin{tabular}{|c|c|c|c|c|c|c|}
\hline Comparison & Category & Category & Studies & OR $(95 \%$ CI $)$ & $P$-value & $P$ for heterogeneity \\
\hline \multirow[t]{12}{*}{ GG vs.GA+ AA } & \multirow[t]{4}{*}{ Ethnicity } & Caucasian & 11 & $0.81(0.65,1.00)$ & 0.054 & $<0.001$ \\
\hline & & Mixed & 1 & $1.09(0.92,1.30)$ & 0.309 & N/A \\
\hline & & African & 2 & $0.85(0.62,1.16)$ & 0.303 & 0.638 \\
\hline & & Asian & 2 & $0.85(0.45,1.63)$ & 0.628 & 0.488 \\
\hline & SOC & $\begin{array}{l}\text { PB } \\
\mathrm{HB}\end{array}$ & $\begin{array}{c}10 \\
6\end{array}$ & $\mathbf{0 . 7 8}(\mathbf{0 . 6 4 , 0 . 9 5 )}$ & $\begin{array}{l}0.012 \\
0.735\end{array}$ & $\begin{array}{c}0.001 \\
<0.001\end{array}$ \\
\hline & \multirow{3}{*}{ HWE } & Docitive & & $1.00(0.1 /, 1.40)$ & 0.150 & 0.001 \\
\hline & & Positive & 11 & $0.87(0.73,1.04)$ & 0.129 & 0.003 \\
\hline & & Negative & 5 & $0.82(0.49,1.39)$ & 0.471 & 0.026 \\
\hline & \multirow[t]{4}{*}{ Method } & PCR & 4 & $1.01(0.43,2.39)$ & 0.982 & 0.010 \\
\hline & & MassARRAY & 3 & $0.87(0.76,1.01)$ & 0.070 & 0.589 \\
\hline & & Taqman & 8 & $0.84(0.65,1.09)$ & 0.189 & 0.001 \\
\hline & & N/A & 1 & $0.76(0.37,1.56)$ & 0.462 & N/A \\
\hline \multirow[t]{12}{*}{ GG vs. AA } & \multirow[t]{4}{*}{ Ethnicity } & Caucasian & 11 & $0.71(0.56,0.90)$ & 0.005 & 0.001 \\
\hline & & Mixed & 1 & $1.11(0.91,1.36)$ & 0.305 & N/A \\
\hline & & African & 2 & $1.09(0.68,1.75)$ & 0.731 & 0.985 \\
\hline & & Asian & 2 & $1.58(0.70,3.54)$ & 0.233 & 0.919 \\
\hline & \multirow[t]{2}{*}{$\mathrm{SOC}$} & PB & 10 & $0.69(0.54,0.88)$ & 0.002 & $<0.001$ \\
\hline & & $\mathrm{HB}$ & 6 & $1.26(0.97,1.64)$ & 0.078 & 0.969 \\
\hline & \multirow[t]{2}{*}{ HWE } & Positive & 11 & $0.81(0.64,1.03)$ & 0.085 & $<0.001$ \\
\hline & & Negative & 5 & $0.81(0.52,1.25)$ & 0.336 & 0.164 \\
\hline & \multirow[t]{4}{*}{ Method } & PCR & 4 & $0.58(0.39,0.86)$ & 0.007 & 0.417 \\
\hline & & MassARRAY & 3 & $0.79(0.66,0.94)$ & 0.008 & 0.676 \\
\hline & & Taqman & 8 & $0.84(0.60,1.17)$ & 0.296 & $<0.001$ \\
\hline & & N/A & 1 & $1.58(0.70,3.54)$ & 0.272 & N/A \\
\hline \multirow[t]{12}{*}{ GA vs. AA } & \multirow[t]{4}{*}{ Ethnicity } & Caucasian & 11 & $0.90(0.72,1.11)$ & 0.328 & $<0.001$ \\
\hline & & Mixed & 1 & $1.03(0.87,1.22)$ & 0.761 & N/A \\
\hline & & African & 2 & $1.25(0.83,1.88)$ & 0.280 & 0.448 \\
\hline & & Asian & 2 & $2.27(0.89,5.82)$ & 0.087 & 0.030 \\
\hline & \multirow[t]{2}{*}{$\mathrm{SOC}$} & PB & 10 & $0.94(0.77,1.14)$ & 0.508 & $<0.001$ \\
\hline & & HB & 6 & $1.26(0.79,1.99)$ & 0.329 & 0.004 \\
\hline & \multirow[t]{2}{*}{ HWE } & Positive & 11 & $0.92(0.79,1.07)$ & 0.265 & 0.021 \\
\hline & & Negative & 5 & $1.35(0.80,2.28)$ & 0.257 & 0.002 \\
\hline & \multirow[t]{4}{*}{ Method } & PCR & 4 & $0.81(0.44,1.51)$ & 0.513 & 0.003 \\
\hline & & Taqman & 3 & $1.00(0.64,1.58)$ & 0.989 & $<0.001$ \\
\hline & & MassARRAY & 8 & $0.99(0.87,1.13)$ & 0.907 & 0.350 \\
\hline & & N/A & 1 & $3.77(1.90,7.47)$ & $<0.001$ & N/A \\
\hline
\end{tabular}

SOC, source of controls; PB, population-based controls; HB, hospital-based controls; HWE: hardy-weinberg equilibrium. 


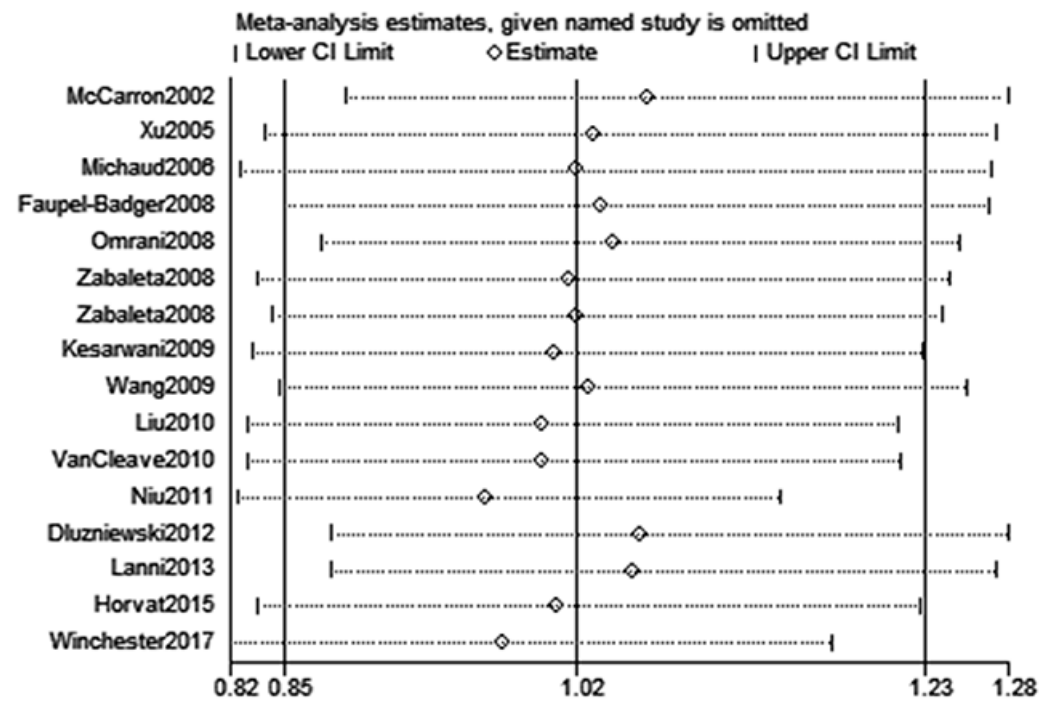

Figure 4: Sensitivity analysis for the association between $I L-10$ gene rs1800896 polymorphism and PCa risk (GA vs. AA).

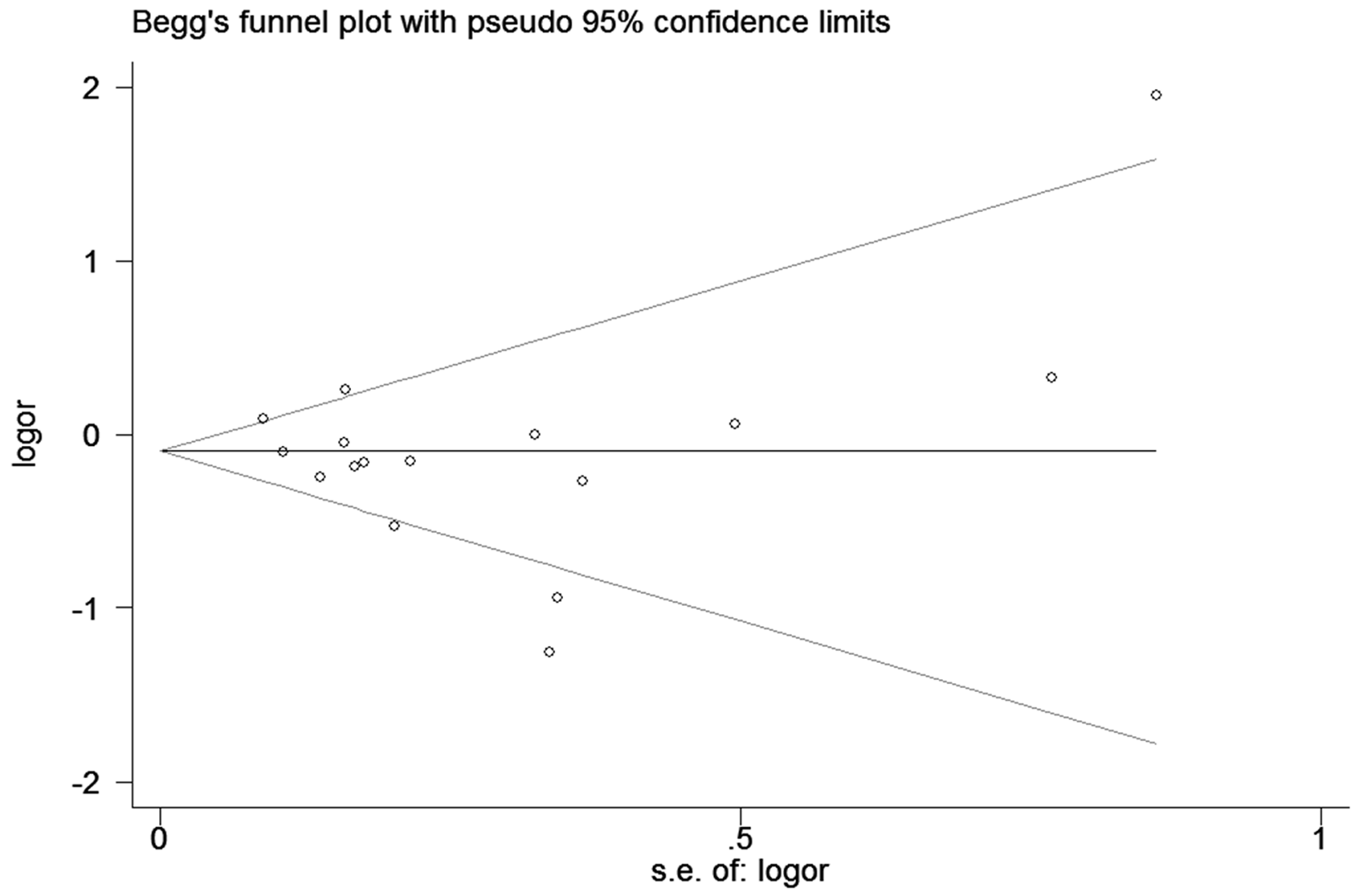

Figure 5: Begg's tests between $I L-10$ rs1800896 polymorphism and PCa risk (GG vs. GA+AA). 
Consequently, the results of Asian groups need be interpreted with caution. Further studies with larger sample sizes is necessary to confirm these hypotheses.

Multiple meta-analyses were conducted to investigate the association between $I L-10$ rs 1800896 polymorphism and cancer risk [40-42]. The meta-analysis conducted by Dai et al. found that $I L-10$ rs 1800896 polymorphism had no association with breast cancer risk in the overall population [41]. However, G allele of rs1800896 was demonstrated to significantly increase susceptibility to gastric cancer and digestive cancer $[40,42]$. In this meta-analysis, we obtained an association between IL-10 rs1800896 polymorphism and the decreased risk of PCa. In summary, the above findings may suggest that $I L-10$ rs1800896 polymorphism has disease-dependent functionality, which may explain the inherent heterogeneity of tumor progression in different types of cancer.

Several potential limitations should be addressed in this meta-analysis. First, no further stratification analyses of other potential factors, such as age and familiar history due to lack of original data. Second, our results were based on unadjusted estimates for confounding factors, which might have affected the final conclusions. Third, the sample sizes of some individual studies were very small, which could deviate from the true results. Fourth, the results should be interpreted with caution due to high heterogeneity. Fifth, some bias may be unavoidable because only articles published in English and Chinese were identified in this study. Finally, the sample sizes of Asian groups were limited.

In conclusion, this meta-analysis indicates that $I L-10$ gene rs1800896 polymorphism is associated with the decreased risk of PCa. $I L-10$ gene may have an ethnicityspecific effect and disease-dependent functionality. Larger studies with more diverse ethnic populations are needed to confirm these results of this meta-analysis.

\section{MATERIALS AND METHODS}

\section{Search strategy and selection criteria}

PubMed, EMBASE, Google and CNKI databases were searched for all relevant articles up to April 1, 2017. The following search terms were used: ("prostate cancer" OR "prostatic neoplasm" OR "prostate carcinoma" OR "prostate neoplasms") AND ("polymorphism" OR "polymorphisms" OR "variant" OR "SNP" OR "SNPs" OR "rs1800896") AND ("Interleukin 10" OR " $I L-10$ " OR "IL10" OR "Cytokine Synthesis Inhibitory Factor"). References in cited studies and review articles were also checked for other relevant articles. We included the latest study when one study overlapped with another one. PCa was diagnosed according to classification criteria.

Studies were included if they: (1) discussed the association between the $I L-10$ rs1800896 variant and PCa;
(2) provided sufficient data for calculating the pooled odds ratio (ORs) with $95 \%$ confidence interval (CI); (3) were case-control studies. Exclusion criteria were: (1) studies containing overlapping data; (2) case reports or reviews; (3) articles investigating other SNPs of $I L-10$ gene.

\section{Data extraction and quality assessment}

Two investigators extracted data from the original studies independently. From each study, the following information was extracted: name of the first author, publication year, country of origin, ethnicity, genotypes of cases and controls, and genotyping method. Authors were contacted to provide supplemental data if data were not available in the relevant articles.

The Newcastle-Ottawa Scales (NOS) were used to assess the quality of the selected studies [43]. Total NOS scores ranged from 0 (worst) to 9 (best). Only the studies with more than 5 stars based on the NOS scale were included in this meta-analysis. The discrepancies were resolved by consensus.

\section{Evaluations of statistical associations}

Pearson's $\chi 2$ test was used to evaluate whether gene frequencies in the controls conformed to HWE. Pooled ORs with corresponding $95 \%$ CIs were calculated to evaluate the strength of the relationship between $I L-10$ rs 1800896 polymorphism and the risk of PCa. Stratification analyses were carried out by ethnicity, SOC, HWE and genotyping method. Heterogeneity between studies was detected by Cochran's Q-statistics. Generally, we considered the presence of significant heterogeneity at the $10 \%$ level of significance and values of $\mathrm{I}^{2}$ exceeding $50 \%$ as an indicator of significant heterogeneity. When no heterogeneity was found with $P>$ 0.10 or $\mathrm{I}^{2}<50 \%$, a fixed-effect model was used. Otherwise, a random-effects model was applied [44]. To detect potential between-study heterogeneity, meta-regression was performed using the following covariates: ethnicity, SOC, HWE and genotyping methods. Sensitivity analysis was conducted to determine the effect of each study on the pooled ORs by omitting each study in turn. Publication bias was evaluated by visual inspection of symmetry of Begg's funnel plot and assessment of Egger's test [45]; $P<0.05$ was regarded as representative of statistical significance. All statistical analyses were performed using the Stata 11.0 software (StataCorp, College Station, TX, USA).

\section{ACKNOWLEDGMENTS}

This work was supported by the National Natural and Science Foundation (81501874), Jiangsu Province Health and Family Planning Commission Foundation (Q201511 and QNRC2016139), Jiaxing Science and Technology Project (2013AY21042-5) and Jiaxing Science and Technology Innovation Team Project (2013-03). 


\section{CONFLICTS OF INTEREST}

The authors declare no conflicts of interest.

\section{REFERENCES}

1. Tabayoyong W, Abouassaly R. Prostate cancer screening and the associated controversy. Surg Clin North Am. 2015; 95:1023-1039.

2. Siegel RL, Miller KD, Jemal A. Cancer statistics, 2017. CA Cancer J Clin. 2017; 67:7-30.

3. Ragsdale JW 3rd, Halstater B, Martinez-Bianchi V. Prostate cancer screening. Prim Care. 2014; 41:355-370.

4. Attard G, Parker C, Eeles RA, Schroder F, Tomlins SA, Tannock I, Drake CG, de Bono JS. Prostate cancer. Lancet. 2016; 387:70-82.

5. Xu J, Lowey J, Wiklund F, Sun J, Lindmark F, Hsu FC, Dimitrov L, Chang B, Turner AR, Liu W, Adami HO, Suh E, Moore JH, et al. The interaction of four genes in the inflammation pathway significantly predicts prostate cancer risk. Cancer Epidemiol Biomarkers Prev. 2005; 14:2563-2568.

6. Mocellin S, Marincola F, Rossi CR, Nitti D, Lise M. The multifaceted relationship between IL-10 and adaptive immunity: putting together the pieces of a puzzle. Cytokine Growth Factor Rev. 2004; 15:61-76.

7. Fortis C, Foppoli M, Gianotti L, Galli L, Citterio $\mathrm{G}$, Consogno G, Gentilini O, Braga M. Increased interleukin-10 serum levels in patients with solid tumours. Cancer Lett. 1996; 104:1-5.

8. Huang S, Ullrich SE, Bar-Eli M. Regulation of tumor growth and metastasis by interleukin-10: the melanoma experience. J Interferon Cytokine Res. 1999; 19:697-703.

9. Richter G, Kruger-Krasagakes S, Hein G, Huls C, Schmitt E, Diamantstein T, Blankenstein T. Interleukin 10 transfected into Chinese hamster ovary cells prevents tumor growth and macrophage infiltration. Cancer Res. 1993; 53:4134-4137.

10. Filella X, Alcover J, Zarco MA, Beardo P, Molina R, Ballesta AM. Analysis of type T1 and T2 cytokines in patients with prostate cancer. Prostate. 2000; 44:271-274.

11. Yu D, Zhong Y, Li X, Li Y, Li X, Cao J, Fan H, Yuan Y, Ji Z, Qiao B, Wen JG, Zhang M, Kvalheim G, et al. ILs-3, 6 and 11 increase, but ILs-10 and 24 decrease stemness of human prostate cancer cells in vitro. Oncotarget. 2015; 6:4268742703. doi: 10.18632/oncotarget.5883.

12. Kingo K, Ratsep R, Koks S, Karelson M, Silm H, Vasar E. Influence of genetic polymorphisms on interleukin-10 mRNA expression and psoriasis susceptibility. J Dermatol Sci. 2005; 37:111-113.

13. Niu WQ. The study on the association between the IL-10 promoter genetic polymorphisms and prostate cancer in Hubei Hans population. Guo Ji Jian Yan Yi Xue Za Zhi. $2011 ; 32: 42-43$
14. Zabaleta J, Lin HY, Sierra RA, Hall MC, Clark PE, Sartor $\mathrm{OA}, \mathrm{Hu} \mathrm{JJ}$, Ochoa AC. Interactions of cytokine gene polymorphisms in prostate cancer risk. Carcinogenesis. 2008; 29:573-578.

15. Winchester DA, Till C, Goodman PJ, Tangen CM, Santella RM, Johnson-Pais TL, Leach RJ, Xu J, Zheng SL, Thompson IM, Lucia MS, Lippman SM, Parnes HL, et al. Association between variants in genes involved in the immune response and prostate cancer risk in men randomized to the finasteride arm in the Prostate Cancer Prevention Trial. Prostate. 2017; 77:908-919.

16. Wang MH, Helzlsouer KJ, Smith MW, Hoffman-Bolton JA, Clipp SL, Grinberg V, De Marzo AM, Isaacs WB, Drake CG, Shugart YY, Platz EA. Association of IL10 and other immune response- and obesity-related genes with prostate cancer in CLUE II. Prostate. 2009; 69:874-885.

17. VanCleave TT, Moore JH, Benford ML, Brock GN, Kalbfleisch T, Baumgartner RN, Lillard JW Jr, Kittles RA, Kidd LC. Interaction among variant vascular endothelial growth factor (VEGF) and its receptor in relation to prostate cancer risk. Prostate. 2010; 70:341-352.

18. Michaud DS, Daugherty SE, Berndt SI, Platz EA, Yeager M, Crawford ED, Hsing A, Huang WY, Hayes RB. Genetic polymorphisms of interleukin-1B (IL-1B), IL-6, IL-8, and IL-10 and risk of prostate cancer. Cancer Res. 2006; $66: 4525-4530$

19. McCarron SL, Edwards S, Evans PR, Gibbs R, Dearnaley DP, Dowe A, Southgate C, Easton DF, Eeles RA, Howell WM. Influence of cytokine gene polymorphisms on the development of prostate cancer. Cancer Res. 2002; 62:3369-3372.

20. Liu J, Song B, Bai X, Liu W, Li Z, Wang J, Zheng Y, Wang Z. Association of genetic polymorphisms in the interleukin-10 promoter with risk of prostate cancer in Chinese. BMC Cancer. 2010; 10:456.

21. Kesarwani P, Ahirwar DK, Mandhani A, Singh AN, Dalela D, Srivastava AN, Mittal RD. IL-10 -1082 G>A: a risk for prostate cancer but may be protective against progression of prostate cancer in North Indian cohort. World J Urol. 2009; 27:389-396

22. Ianni M, Porcellini E, Carbone I, Potenzoni M, Pieri AM, Pastizzaro CD, Benecchi L, Licastro F. Genetic factors regulating inflammation and DNA methylation associated with prostate cancer. Prostate Cancer Prostatic Dis. 2013; 16:56-61.

23. Horvat V, Mandic S, Marczi S, Mrcela M, Galic J. Association of IL-1beta and IL-10 polymorphisms with prostate cancer risk and grade of disease in Eastern Croatian population. Coll Antropol. 2015; 39:393-400.

24. Faupel-Badger JM, Kidd LC, Albanes D, Virtamo J, Woodson K, Tangrea JA. Association of IL-10 polymorphisms with prostate cancer risk and grade of disease. Cancer Causes Control. 2008; 19:119-124. 
25. Dluzniewski PJ, Wang MH, Zheng SL, De Marzo AM, Drake CG, Fedor HL, Partin AW, Han M, Fallin MD, Xu $\mathrm{J}$, Isaacs WB, Platz EA. Variation in IL10 and other genes involved in the immune response and in oxidation and prostate cancer recurrence. Cancer Epidemiol Biomarkers Prev. 2012; 21:1774-1782.

26. Omrani $\mathrm{MD}$, Bazargani $\mathrm{S}$, Bageri M. Interlukin-10, interferon- $\gamma$ and tumor necrosis factor- $\alpha$ genes variation in prostate cancer and benign prostatic hyperplasia. Curr Urol. 2008; 2:175-180.

27. El Khoury L, Posthumus M, Collins M, Handley CJ, Cook J, Raleigh SM. Polymorphic variation within the ADAMTS2, ADAMTS14, ADAMTS5, ADAM12 and TIMP2 genes and the risk of Achilles tendon pathology: a genetic association study. J Sci Med Sport. 2013; 16:493-498.

28. Mannino MH, Zhu Z, Xiao H, Bai Q, Wakefield MR, Fang Y. The paradoxical role of IL-10 in immunity and cancer. Cancer Lett. 2015; 367:103-107.

29. Gibson AW, Edberg JC, Wu J, Westendorp RG, Huizinga TW, Kimberly RP. Novel single nucleotide polymorphisms in the distal IL-10 promoter affect IL-10 production and enhance the risk of systemic lupus erythematosus. J Immunol. 2001; 166:3915-3922.

30. Yang Y, Fa X. Role of IL-10 gene polymorphisms on the susceptibility for esophageal cancer and its association with environmental factors. Int J Clin Exp Pathol. 2015; 8:9580-9585.

31. Li YF, Yang PZ, Li HF. Functional polymorphisms in the IL-10 gene with susceptibility to esophageal, nasopharyngeal, and oral cancers. Cancer Biomark. 2016; 16:641-651.

32. Kuo WH, Huang CY, Fu CK, Hsieh YH, Liao CH, Hsu CM, Huang YK, Tsai CW, Chang WS, Bau DT. Effects of interleukin-10 polymorphisms and smoking on the risk of gastric cancer in Taiwan. In Vivo. 2014; 28:967-971.

33. Miteva LD, Stanilov NS, Deliysky TS, Stanilova SA. Significance of $-1082 \mathrm{~A} / \mathrm{G}$ polymorphism of IL10 gene for progression of colorectal cancer and IL-10 expression. Tumour Biol. 2014; 35:12655-12664.

34. Shao N, Xu B, Mi YY, Hua LX. IL-10 polymorphisms and prostate cancer risk: a meta-analysis. Prostate Cancer Prostatic Dis. 2011; 14:129-135.

35. Zou YF, Wang F, Feng XL, Tian YH, Tao JH, Pan FM, Huang F. Lack of association of IL-10 gene polymorphisms with prostate cancer: evidence from 11,581 subjects. Eur J Cancer. 2011; 47:1072-1079.

36. Ruan XL, Li S, He ZQ, Huang JY, Zhang C, Weng H. Metaanalysis on the possible role of interluekin-10 rs1800896 polymorphism in association with prostate cancer susceptibility. Int J Clin Exp Med. 2017; 10:1967-1975.

37. Winchester DA, Till C, Goodman PJ, Tangen CM, Santella RM, Johnson-Pais TL, Leach RJ, Xu J, Zheng SL, Thompson IM, Lucia MS, Lippmann SM, Parnes HL, et al. Variation in genes involved in the immune response and prostate cancer risk in the placebo arm of the Prostate Cancer Prevention Trial. Prostate. 2015; 75:1403-1418.

38. de Waal Malefyt R, Haanen J, Spits H, Roncarolo MG, te Velde A, Figdor C, Johnson K, Kastelein R, Yssel H, de Vries JE. Interleukin 10 (IL-10) and viral IL-10 strongly reduce antigen-specific human $\mathrm{T}$ cell proliferation by diminishing the antigen-presenting capacity of monocytes via downregulation of class II major histocompatibility complex expression. J Exp Med. 1991; 174:915-924.

39. Turner DM, Williams DM, Sankaran D, Lazarus M, Sinnott PJ, Hutchinson IV. An investigation of polymorphism in the interleukin-10 gene promoter. Eu J Immunogenet. 1997; $24: 1-8$.

40. Ni P, Xu H, Xue H, Lin B, Lu Y. A meta-analysis of interleukin-10-1082 promoter polymorphism associated with gastric cancer risk. DNA Cell Biol. 2012; 31:582-591.

41. Dai ZJ, Wang XJ, Zhao Y, Ma XB, Kang HF, Min WL, Lin S, Yang PT, Liu XX. Effects of interleukin-10 polymorphisms (rs1800896, rs1800871, and rs1800872) on breast cancer risk: evidence from an updated meta-analysis. Genetic Test Mol Biomarkers. 2014; 18:439-445.

42. Li C, Tong W, Liu B, Zhang A, Li F. The $-1082 \mathrm{~A}>\mathrm{G}$ polymorphism in promoter region of interleukin-10 and risk of digestive cancer: a meta-analysis. Sci Rep. 2014; 4:5335.

43. Stang A. Critical evaluation of the Newcastle-Ottawa scale for the assessment of the quality of nonrandomized studies in meta-analyses. Eur J Epidemiol. 2010; 25:603-605.

44. Higgins JP, Thompson SG. Quantifying heterogeneity in a meta-analysis. Stat Med. 2002; 21:1539-1558.

45. Egger M, Davey Smith G, Schneider M, Minder C. Bias in meta-analysis detected by a simple, graphical test. BMJ. 1997; 315:629-634. 